\title{
The Effect of 6-Azauridine Administration on De Novo Pyrimidine Production in Chronic Myelogenous Leukemia *
}

\author{
V. H. Bono, JR., S. M. Weissman, and E. Frei III \\ (From the Medicine Branch and Metabolism Service of the National Cancer Institute, \\ Bethesda, Md.)
}

6-Azauridine [2-ribofuranosyl-as-triazine-3,5$(2 \mathrm{H}, 4 \mathrm{H})$-dione] ( $\mathrm{AzUR})$ is a pyrimidine nucleoside analog that has been employed in the experimental therapy of neoplastic disease (1). $\mathrm{AzUR}$ is converted by uridine kinase to 6 -azauridylic acid (AzUMP), which competitively inhibits the decarboxylation of orotidylic acid (OMP), an essential step in the biosynthesis of pyrimidines $(2,3)$. During therapy of chronic myelogenous leukemia (CML) with AzUR, urinary excretion of orotic acid (OA), orotidine (OR) (4), and carbamylaspartic acid $(\mathrm{CAA})^{1}$ occurs. Because the sum of these urinary metabolites is in the range of 15 to 20 mmoles per day, it has been proposed that the inhibition of orotidylic acid decarboxylase by 6 -azauridylic acid (3) mediates an overproduction of pyrimidine precursors, perhaps as a result of a decrease in the rate of production of decarboxylated pyrimidines. A diagram of relevant metabolic paths is presented in Figure 1.

An attempt was made to measure the effect of $\mathrm{AzUR}$ on the rate of pyrimidine production. The incorporation of ring-labeled $\mathrm{C}^{14}$-orotic acid (OA6- $\mathrm{C}^{14}$ ) into urinary pseudouridine has been used to estimate the rate of de novo pyrimidine production in subjects with carcinoma (5). This estimate involves the assumption of a steady state. The method requires only the determination of total isotope incorporated into an inert end product and involves an expression of integrated specific activities that will be presented in the Methods. With this technique the rate of de novo

* Submitted for publication May 6, 1963; accepted March 12, 1964.

Presented in part at the Fifty-fourth Annual Meeting of the American Association for Cancer Research, Toronto, Canada, May 24, 1963.

1 Unpublished data from this laboratory. pyrimidine production in patients with CML was determined. During therapy with AzUR this technique of measuring pyrimidine production could not be used for both technical and theoretical reasons. The theoretical objections are that a steady state would have to be assumed for a period of 18 days, the period of isotope incorporation into pseudouridine, during which marked changes in the pool size of RNA could occur as a result of $\mathrm{AzUR}$ administration. In addition, this technique would assume that there had been no fluctuation, induced by AzUR, in the percentage of newly synthesized pyrimidines that are converted to pseudouridine during this period. For these reasons and additionally because of the occurrence of interfering unidentified ultraviolet absorbing materials in the pseudouridine fraction, another technique of measuring pyrimidine production was necessary. By analogous reasoning, during therapy with $\mathrm{AzUR}$ the incorporation of orotic acid carboxyl- $\mathrm{C}^{14}$ (OA-7- $\mathrm{C}^{\mathbf{1 4}}$ ) into urinary OR can be used to estimate the OMP production rate. In this case the period of isotopic incorporation is measured in hours, requiring a steady state for only a short period of time, and the only pyrimidine pools that must meet the steady state requirements are those before the point of OMP decarboxylation, changes in the pool size of decarboxylated pyrimidines and of RNA having no effect. The outline of the pyrimidine biosynthetic pathway in Figure 1 demonstrates that the OMP production rate minus the urinary $\mathrm{OR}$ excretion rate estimates the UMP production rate and that the OMP production rate plus the urinary OA excretion rate estimate the de novo rate of pyrimidine production.

As was anticipated, the rate of de novo pyrimidine production during therapy with $\mathrm{AzUR}$ was greater than the pretreatment rate. In addition, 


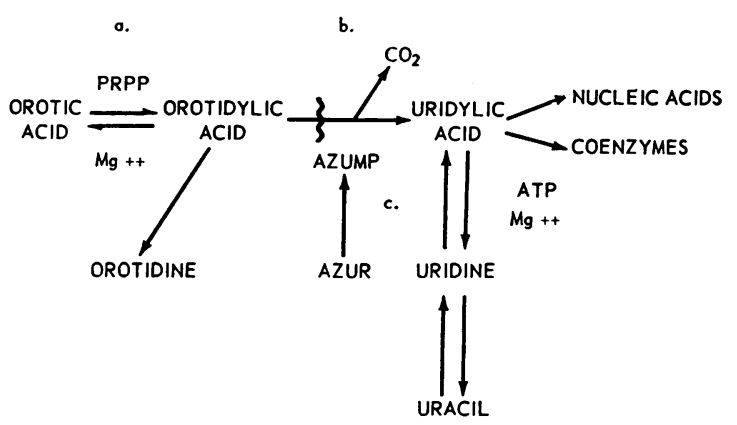

o. Orotidylic Acid Pyrophosphorylose

b. Orotidylic Acid Decorboxylose

c. Uridine Kinase

Fig. 1. Outline of pathway of de novo pyrimidine BIOSYNTHESIS AS EFFECTED BY 6-AZAURIDINE (AzUR). AzUMP $=6$-azauridylic acid $; \quad P R P P=$ phosphoribosyl pyrophosphate.

the rate of production of decarboxylated pyrimidines was greater during AzUR therapy than during the control period. This effect would not be expected as a result of inhibition of orotidylic acid decarboxylation and indicates that $\mathrm{AzUR}$ may have additional mechanisms of action, or that the primary blockade caused by 6 -azauridine administration may result in secondary changes in pyrimidine metabolism.

\section{Methods}

Orotic acid and orotidine were isolated from samples of urine by Dowex-1-formate column chromatography and stepwise elution with formic acid and ammonium formate according to a previously described method (4). The concentration of pyrimidine in each pooled peak was determined by its ultraviolet absorption in ammonium formate (4). The entire fraction, usually containing about $1 \mu$ mole of pyrimidine in 6 mmoles of ammonium formate, was dried by lyophilization, dissolved in $2.0 \mathrm{ml}$ water, and a $1.8-\mathrm{ml}$ sample added to $18 \mathrm{ml}$ of Bray's liquid scintillation solution (6). Radioactivity was determined in a liquid scintillation spectrometer, and variations in counting efficiency were determined by the use of an internal standard.

Radioactivity in urinary carbamylaspartic acid was determined by a carrier technique to facilitate identification of the compound. The urine sample and chromatography column were prepared as for the isolation of OA and OR but for the addition of $7.5 \mu$ moles of CAA to the sample. The CAA was eluted before OR and $\mathrm{OA}$ with $0.05 \mathrm{M}$ ammonium formate adjusted to pH 3.2 with formic acid (7). It was identified by drying $0.1-\mathrm{ml}$ samples on $4-\times 4-\mathrm{mm}$ filter paper squares in small glass vials at $40^{\circ} \mathrm{C}$ in vacuo and then spot testing with $10 \mu \mathrm{l}$ of a solution of $4 \mathrm{~g} p$-dimethylaminobenzaldehyde per $100 \mathrm{ml} 1 \mathrm{M} \mathrm{HCl}(7)$. The CAA peak was pooled, dried by lyophilization, dissolved in water, and the radioactivity determined as for $O A$ and $O R$.

Urinary pseudouridine was isolated by a previously described column chromatography procedure (8). Radioactivity assays were performed in a liquid scintillation counter as previously described (5). Sample sizes were chosen such that $2 \mathrm{SD}$ of the count rate were less than $7 \%$ of the net observed count rate.

Urinary pseudouridine content was determined in duplicate on weekly urine pools and estimated by its optical density at $260 \mathrm{~m} \mu$ with an extinction coefficient of $8.6 \times$ $10^{3}$ at $\mathrm{pH} 7$. Specific activity curves were linearly extrapolated to zero specific activity, and total radioactivity was estimated by graphic integration.

Total urinary radioactivity was determined by adding $20 \mu \mathrm{l}$ of whole urine to $18 \mathrm{ml}$ Bray's solution and correcting the count rate by the use of an internal standard.

Three-minute expiratory air samples were collected in rubber balloons. The carbon dioxide was trapped by bubbling it through $250 \mathrm{ml} 1 \mathrm{M} \mathrm{NaOH}$ over a 20-minute period. Fourteen-ml samples were placed in a tared counting bottle, and $\mathrm{BaCO}_{3}$ was precipitated by adding $2 \mathrm{ml} 4.37 \mathrm{M} \mathrm{NH}_{4} \mathrm{NO}_{3}$ and $2.8 \mathrm{ml} 1.44 \mathrm{M} \mathrm{BaCl}_{2}$. The precipitate was allowed to settle overnight and then packed by centrifugation. It was washed twice with water, twice with absolute ethanol, and then dried to constant weight at $50^{\circ} \mathrm{C}$ in vacuo. Loss during washing was in the range of 1 to $2 \%$ as estimated from pooled washing fluids. The weight of $\mathrm{BaCO}_{3}$ was determined by difference. It was then coarsely powdered within the counting bottle with a fine spatula, suspended in a thixotropic gel (9), and counted in a liquid scintillation counter. The size of the $\mathrm{BaCO}_{3}$ particle did not influence the count rate (9). The relative counting efficiency and self-absorption curve of this system were found to be the same as that previously reported (9). The relative counting efficiency of carbon ${ }^{14}$ in thixotropic gel and in Bray's solution was determined by combusting a known sample of OA-7-C $\mathrm{C}^{14}$ in a closed chamber (10). One hundred per cent recovery of counts as carbon dioxide- $\mathrm{C}^{14}$ after absorption in $1 \mathrm{~N} \mathrm{NaOH}$ indicated no difference in the counting efficiency of either OA-7-C $\mathrm{C}^{14}$ or carbon dioxide- $\mathrm{C}^{14}$ in Bray's solution. A sample of the carbon dioxide- $\mathrm{C}^{14}$ was converted to $\mathrm{BaCO}_{3}$ and counted in thixotropic gel. The count rate, at $0 \mathrm{mg}$ self absorption, was $116 \%$ of the count rate in Bray's solution. Total respiratory carbon dioxide- $\mathrm{C}^{14}$ was estimated by graphic integration of interval determinations.

Fecal radioactivity was determined on a 3-day collection after the dose of isotope. The specimen, collected in a tared paint can containing phenol, was homogenized in $1 \mathrm{~L}$ of water in an automatic shaker. A $\frac{1}{2}-\mathrm{ml}$ sample was dried and combusted in a closed vessel. The resulting carbon dioxide was trapped in alkali and counted in a liquid scintillation counter.

Adults with uncomplicated CML were studied. Some had been previously treated, but none had had significant hematopoietic depression by previous therapy for at least 1 month before the determination of the control rate of de novo pyrimidine production. All patients were am- 
bulatory, had had no recent weight loss, and did not require any form of supportive therapy. Their hemoglobin concentration was $10 \mathrm{~g}$ per $100 \mathrm{ml}$ or greater, and all of the patients were in the chronic or stable phase of their disease as evidenced by the fact that circulating promyelocytes and myeloblasts did not exceed $10 \%$. In each case, the Philadelphia chromosome was present, and the leukocyte alkaline phosphatase activity was abnormally low.

The study was divided into a control period and a therapy period. All patients were begun on a purine-free, isocaloric diet containing $70 \mathrm{~g}$ protein (8) for 5 days before the control study and maintained on this diet until the end of the therapy period. The control rate of $d e$ novo pyrimidine production was determined by the intravenous infusion of $25 \mu \mathrm{c}$ ( 2 to $4 \mu \mathrm{c}$ per $\mu$ mole) of OA-6-C $C^{14}$ over a $1 \frac{1}{2}$ hour period. Urine was collected in daily intervals for the following 20 to 30 days. On days 21 to 32, therapy with AzUR was begun with a continuous intravenous infusion of a dose of $180 \mathrm{mg}$ per $\mathrm{kg}$ body weight per day. On the indicated day of therapy, $20 \mu \mathrm{c}$ (4 $\mu \mathrm{c}$ per $\mu$ mole) of orotic-acid carboxyl-C ${ }^{14}$ was infused at a constant rate over an 8-hour period. Urine was collected in serial fractions that day and daily thereafter. Timed expiratory air samples were collected every 2 hours during the infusion and at increasing intervals over the next 24-hour period. Therapy with AzUR was terminated when clinically indicated.

The rate of de novo pyrimidine production in the control period was estimated by a method previously described and calculated as (pseudouridine production rate)/ (fraction of total isotope incorporated into pseudouridine) (5). In an analogous manner, the rate of production of orotidylic acid can be calculated as (orotidine production rate)/(percentage of total isotope incorporated into orotidine).

Both cases may be analyzed by the compartmental model that follows:

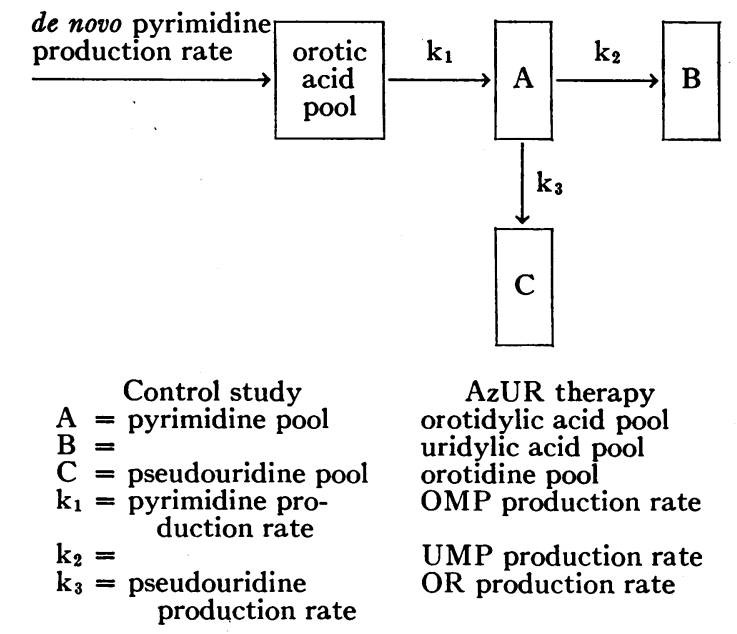

It can be shown that $k_{1}=k_{3}$ /(fraction of isotope introduced into $\mathrm{A}$ that is incorporated into $\mathrm{C}$ at infinite time). 


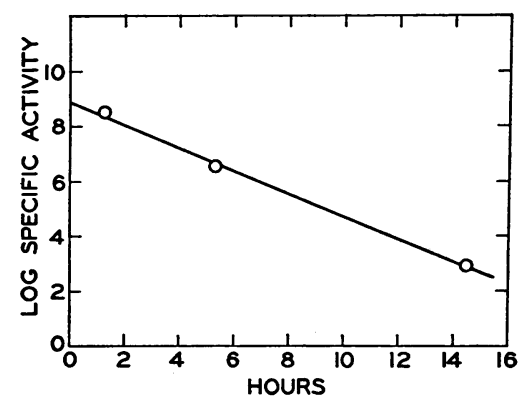

Fig. 2. Natural LOGaRithM OF SPECIFIC ACtivity (COUNTS PER MINUTE PER MICROMOLE) OF URINARY OROTIC ACID AFTER AN INTRAVENOUS TRACER DOSE OF $20 \mu \mathrm{C}$ OROTIC ACID-7-C ${ }^{14}$ IN PATIENT G. H. ON DAY 7 OF THERAPY WITH AZAURIDINE.

This analysis requires only the accurate determination of the rate of production of the end product and the total isotope incorporated into the end product. It is independent of the actual specific activity of any intermediate or product or any relation between them as a function of time.

Since $k_{3}$ can be measured directly from the urine during $A z U R$ therapy, $\left(k_{1}-k_{8}\right)$ gives a value for $k_{2}$ that is the rate of production of UMP. In subsequent usage the rate of de novo pyrimidine production while on therapy with AzUR will mean the de novo rate of production of orotic acid. This is estimated by the sum of $k_{1}$ and the urinary excretion rate of orotic acid.

\section{Results}

Four patients were treated with a continuous intravenous infusion of AzUR. Data relating to the duration of therapy, therapeutic effect, and day of study on which de novo pyrimidine production rates were determined are present in Table I.

In a preliminary study the turnover time and pool size of orotic acid and turnover time of orotidine were determined in $\mathrm{G}$. $\mathrm{H}$. on day 7 of therapy. A dose of $20 \mu \mathrm{c}$ of OA-7-C $\mathrm{C}^{14}$ was infused over a $1 \frac{1}{2}$ hour period. Specific activities of urinary orotic acid and orotidine were determined on interval urine collections. From the slope and zero time intercept of a plot of the natural logarithm of specific activity, a pool size of 1.6 mmoles orotic acid and a turnover time of 2.2 hours were determined (Figure 2). An independent check on these figures was possible, since a pool of 1.6 mmoles that is turning over every 2.2 hours would result in the excretion of 17.5 mmoles during a 24-hour period. This is in reasonably good
TABLE II

Pyrimidine production during control period

\begin{tabular}{|c|c|c|c|c|}
\hline \multirow[t]{2}{*}{ Patient } & \multicolumn{2}{|c|}{$\begin{array}{l}\text { Daily excretion of } \\
\text { pseudouridine }\end{array}$} & \multirow{2}{*}{$\begin{array}{c}\begin{array}{c}\text { Incor- } \\
\text { poration } \\
\text { into pseu- } \\
\text { douridine* }\end{array} \\
\%\end{array}$} & \multirow{2}{*}{$\begin{array}{c}\begin{array}{c}\text { De novo } \\
\text { pyrimidine } \\
\text { production } \\
\text { rate }\end{array} \\
\begin{array}{c}\text { mmoles } \\
\text { day }\end{array}\end{array}$} \\
\hline & $m g / d a y$ & mmoles/day & & \\
\hline $\begin{array}{l}\text { G.H. } \\
\text { R.C. } \\
\text { H.C. }\end{array}$ & $\begin{array}{l}80.1 \\
99.8 \\
49.6\end{array}$ & $\begin{array}{l}0.33 \\
0.41 \\
0.20\end{array}$ & $\begin{array}{l}3.22 \\
2.57 \\
4.8\end{array}$ & $\begin{array}{r}10.2 \\
15.9 \\
4.2\end{array}$ \\
\hline
\end{tabular}

* Per cent of dose of orotic acid-6-C ${ }^{14}$ incorporated into urinary pseudouridine.

agreement with the gross excretion of orotic acid during the 24 hours after the isotope infusion, which was 13.8 mmoles.

The data for orotidine indicate a period of isotope enrichment of the orotidine pool followed by a fall in specific activity consistent with dilution of a pool of labeled orotidine by unlabeled orotidine (Figure 3). The turnover time of this pool was between 16 and 22 hours. Extrapolation to zero time specific activity results in a value for a pool size between 2 and 5 mmoles of orotidine as a maximal estimate.

The de novo pyrimidine production rate in three patients was determined before AzUR therapy. Table II presents the percentage of incorporation of OA-6-C ${ }^{14}$ into pseudouridine and its daily rate of excretion. The de novo pyrimidine production rate was found to range from 4.2 to 15.9 mmoles per day. This did not directly correlate with disease activity as measured by organomegaly and peripheral leukocyte count.

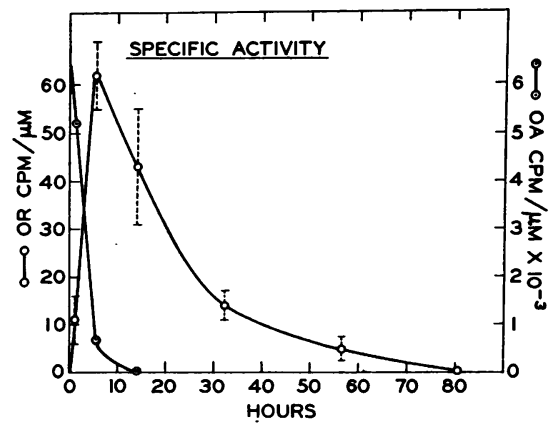

Fig. 3. SPECIFIC ACTIVITY OF URINARY OROTIC ACID (OA) AND OROTIDINE (OR) AFTER AN INTRAVENOUS TRACER DOSE OF $20 \mu \mathrm{C}$ OROTIC ACID-7-C ${ }^{14}$ IN PATIENT G. H. ON DAY 7 OF THERAPY WITH AZAURIDINE. 95\% confidence limits for the count rate are indicated. 
TABLE III

Isotope recovery in orotic acid-7-C ${ }^{14}$ experiments*

\begin{tabular}{|c|c|c|c|c|c|c|c|}
\hline \multirow[b]{2}{*}{ Patient } & \multirow{2}{*}{$\begin{array}{l}\text { Day of } \\
\text { AzUR }\end{array}$} & \multicolumn{4}{|c|}{ Urinary isotope } & \multirow{2}{*}{$\begin{array}{c}\text { Respiratory } \\
\mathrm{C}^{14} \mathrm{O}_{2}\end{array}$} & \multirow{2}{*}{$\underset{C^{14}}{\text { Missing }}$} \\
\hline & & OAt & OR & $\mathrm{x} \ddagger$ & Total & & \\
\hline $\begin{array}{l}\text { G.H. } \\
\text { M.O. } \\
\text { R.C. } \\
\text { H.C. }\end{array}$ & $\begin{array}{r}20 \\
2 \\
28 \\
2\end{array}$ & $\begin{array}{l}50.4 \\
66.7 \\
53.8 \\
55.5\end{array}$ & $\begin{array}{r}4.8 \\
12.7 \\
3.2 \\
11.8\end{array}$ & $\begin{array}{l}6.6 \\
3.0 \\
1.3 \\
7.1\end{array}$ & $\begin{array}{l}61.8 \\
82.4 \\
58.3 \\
74.4\end{array}$ & $\begin{array}{l}20.6 \\
14.1 \\
26.0 \\
15.4\end{array}$ & $\begin{array}{r}17.6 \\
3.5 \\
15.7 \\
10.2\end{array}$ \\
\hline
\end{tabular}

* Figures are cumulative percentage of initial isotope dose recovered in each substance:

$\dagger \mathrm{OA}=$ orotic acid $\mathrm{OR}=$ orotidine.

$\ddagger$ Urinary isotope unaccountable as orotic acid and orotidine.

In patients on $A z U R$, the distribution of a dose of OA-7-C $\mathrm{C}^{14}$ was determined in urine, expired air, and feces. Table III presents a summary of this distribution. In each case the total urinary radioactivity exceeded the sum of urinary $\mathrm{OA}$ and $\mathrm{OR}$ radioactivity by 3 to $6 \%$. Although this probably represents experimental error, the possibility of incorporation into precursors through retrograde flow of isotope was investigated. No radioactivity in carrier CAA added to the urine of two patients (H. C. and G. H.) could be demonstrated under conditions that would detect 1 to $2 \%$ of the dose. The specific activity of respiratory carbon dioxide reached a maximum 2 hours after the start of the infusion, remained there until the end of the infusion at 8 hours, and thereafter decreased exponentially. A 3-day stool collection from one patient ( $R$. C.) was assayed for radioactivity. No radioactivity was found under conditions that would detect $0.2 \%$ of the dose. In each case the sum of urinary and respiratory $\mathrm{C}^{14}$ is less than the initial dose. In view of the evidence that there is no fecal excretion of $\mathrm{C}^{14}$ and since there is no evidence of retrograde flow back past CAA, the most likely explanation is that

TABLE IV

Orotic acid and orotidine excretion during $A z U R$ therapy

\begin{tabular}{cccc}
\hline \hline Patient & \multicolumn{1}{c}{$\mathrm{OA}^{*}$} & \multicolumn{1}{c}{ OR* } & OR $\dagger$ \\
\hline & mmoles/day & mmoles/day & mmoles/day \\
G.H. & 10.0 & 9.4 & 6.0 \\
R.C. & 18.5 & 8.9 & 7.5 \\
H.C. & 8.0 & 4.6 & 4.8 \\
M.O. & 19.1 & 7.0 & 6.3
\end{tabular}

* Rate of urinary excretion during the interval of orotic acid-7-C ${ }^{14}$ infusion.

$\dagger$ Average urinary excretion rate for 5 days after dose of orotic acid-7-C $\mathrm{C}^{14}$. the respiratory carbon dioxide- $\mathrm{C}^{14}$ is in error and its true value is the sum of the measured carbon dioxide- $\mathrm{C}^{14}$ and the missing carbon- $\mathrm{C}^{14}$.

Table IV presents the rate of excretion of OR and $\mathrm{OA}$ in millimoles per day during the interval of OA-7-C ${ }^{14}$ infusion as well as the 5-day average excretion of OR after the dose. Since the orotidine pool has a long turnover time (16 to 22 hours), the rate of excretion of OR during the isotope infusion may not represent the rate of production. The 5-day average rate is, however, approximately the same as the interval rate in three of the four cases, indicating a relatively steady state.

In the calculation of the de novo pyrimidine production rate and uridylic acid production rate during AzUR therapy, the rate of production of orotidine was taken as the interval rate except for one subject (G. H.) where the 5-day average was used. The total dose of isotope incorporated into OMP was estimated as the dose of isotope administered minus the amount of isotope excreted as unchanged orotic acid. The values are presented in Table $\mathrm{V}$ along with the control values as previously presented in Table II.

TABLE V

Pyrimidine production during AzUR therapy, estimated by urinary orotidine radioactivity

\begin{tabular}{|c|c|c|c|c|}
\hline \multirow[b]{2}{*}{ Name } & \multirow[b]{2}{*}{$\begin{array}{l}\text { Day of } \\
\text { adminis- } \\
\text { tration }\end{array}$} & \multirow[b]{2}{*}{$\begin{array}{l}\text { Control } \\
\text { period } \\
\text { de novo } \\
\text { production }\end{array}$} & \multicolumn{2}{|c|}{ AzUR administration } \\
\hline & & & $\begin{array}{c}\text { Total } \\
\text { de novo } \\
\text { pyrimidine } \\
\text { production }\end{array}$ & $\underset{\text { production }}{\text { UMP* }}$ \\
\hline & & mmoles/day & mmoles/day & mmoles/day \\
\hline G.H. & 20 & 10.2 & 72.0 & 56.0 \\
\hline R.C. & 8 & 15.9 & 147.6 & 120.2 \\
\hline H.C. & 2 & 4.2 & 29.5 & 13.3 \\
\hline M.O. & 2 & & 37.8 & 11.8 \\
\hline
\end{tabular}

*UMP = uridine monophosphate. 
Methods of calculating pyrimidine production rates that utilize the steady state specific activity of $\mathrm{OA}$ are not applicable because they also involve the assumption that the specific activity of the OR formed will equal that of the urinary OA. This clearly is not the case because of the unequal cumulative specific activities of these two urinary products. This would imply that even during a period of constant infusion of isotopic $\mathrm{OA}$, the extracellular specific activity remains greater than the established intracellular specific activity.

If, however, there were two cell populations, one making no endogenous $\mathrm{OA}$, utilizing serum isotopic OA, and decarboxylating all of the synthesized OMP, and the other making endogenous $\mathrm{OA}$, not utilizing serum isotopic OA, and converting all of the synthesized OMP into OR, then the UMP production rate as estimated from the previously presented calculations would be greater than the true rate. Under these extreme conditions, the specific activity of serum OA equals the specific activity of the $\mathrm{CO}_{2}$ produced. Thus, the rate of production of OMP = (percentage of isotope in $\mathrm{CO}_{2}$ /percentage of isotope in urinary $\mathrm{OA}$ ) times the rate of excretion of OA. This estimate represents the minimal UMP production rate. Table VI presents these rates calculated either by using isotope recovered as respiratory $\mathrm{CO}_{2}$, or by estimating respiratory isotopic $\mathrm{CO}_{2}$ from the difference between administered isotope and recovered urinary isotope. The latter estimate is more likely accurate in view of evidence that the only demonstrable pathway for flow of isotope was into urine and respiratory $\mathrm{CO}_{2}$.

An estimate of the amount of label entering cells excreting orotidine may be made under the assumptions that cells excreting orotidine are not decarboxylating any orotic acid, and that these cells are also excreting orotic acid, with the ratio of orotic acid to orotidine excreted being at least as high as that found in the urine. Under these conditions [total isotope in orotidine $\times(1+$ urinary $\mathrm{OA} /$ urinary $\mathrm{OR})] /[$ total isotope in respiratory $\mathrm{CO}_{2}$ ] would give the ratio of labeled orotic acid entering cells excreting orotidine to labeled orotic acid entering unblocked cells. These calculations indicate that a minimum of $25 \%$ of the labeled orotic acid entering cells penetrates
TABLE VI

Minimal estimate of UMP production derived from urinary orotic acid specific activity and respiratory isotopic $\mathrm{CO}_{2}$

\begin{tabular}{cccc}
\hline \hline & $\begin{array}{c}\text { Control } \\
\text { de novo } \\
\text { production }\end{array}$ & \multicolumn{2}{c}{ AzUR therapy } \\
\cline { 3 - 4 } Subject & $\begin{array}{c}\text { UMP pro- } \\
\text { duction* }\end{array}$ & $\begin{array}{c}\text { UMP pro- } \\
\text { duction† }\end{array}$ \\
\hline & mmoles/day & mmoles/day & mmoles/day \\
G.H. & 10.2 & $>4.1$ & $>7.6$ \\
M.O. & & $>4.1$ & $>5.0$ \\
R.C. & 15.9 & $>8.9$ & $>14.3$ \\
H.C. & 4.2 & $>2.2$ & $>3.7$
\end{tabular}

* Calculation based on isotopic $\mathrm{CO}_{2}$ recovered as estimated from graphic integration of data from interval respiratory $\mathrm{CO}_{2}$ samples.

$\dagger$ Calculation based on isotopic $\mathrm{CO}_{2}$ as estimated from the difference between the administered dose of isotope and total urinary isotope recovered.

cells blocked in OMP decarboxylation. This estimate would be unduly low if cells excreting OR were also decarboxylating some OMP.

Finally, in terms of the relatively short duration of the studies performed during drug administration, steady-state conditions would appear to have been approximated reasonably well, since the leukocyte count of these subjects and their excretion of pyrimidine products were relatively constant.

\section{Discussion}

In a previous report (5) an estimate of pyrimidine production in three subjects with metastatic carcinoma varied between 4.0 and 5.6 mmoles per day. In our study three subjects with untreated CML produced 4.2 to 15.9 mmoles per day. This is consistent with the elevated urinary pseudouridine frequently noted in this disease (11).

The pyrimidine analog AzUR has been demonstrated to exert an effect on pyrimidine metabolism by first acting as a substrate for uridine kinase, being converted to 6-azauridine 5-monophosphate (AzUMP) and then acting as a competitive inhibitor of orotidylic acid decarboxylase (3). In animal and human studies the prior administration of $\mathrm{AzUR}$ markedly reduced the release of respiratory carbon dioxide- $\mathrm{C}^{14}$ from intravenously administered OA-carboxyl $\mathrm{C}^{14}(12,13)$. This has been presented as evidence for a prompt whole body inhibition of orotidylic acid decarboxylation produced by AzUR. Similarly, a decrease in orotic acid decarboxylating activity of human 
leukemic leukocytes, in vitro, has been demonstrated during therapy with AzUR, and this inhibition has been correlated with the effectiveness of the drug in controlling the leukocyte count (14). Although AzUR produces a prompt fall in leukemic leukocyte counts, presumably by its effect on orotidylic acid decarboxylase, it is remarkably nontoxic to other tissues (1).

Overproduction of pyrimidine precursors during AzUR therapy was suspected because of the large urinary quantities of $\mathrm{OA}$ and $\mathrm{OR}$. It has been proposed that this is the result of release of feedback control, as an indirect result of a deficit in the production of UMP (uridine monophosphate).

The finding that one set of estimates of whole body rates of production of UMP in three patients on continuous AzUR therapy varied from 3 to 8 times the control rate is at variance with the acute effects of $\mathrm{AzUR}$ and implies that a deficit of UMP may not be the cause of chronic overproduction. One might postulate that a derivative of $\mathrm{AzUR}$ could interfere with the production of a feedback controlling pyrimidine at a point beyond orotidylic acid decarboxylase, interfere with its action at the site of feedback inhibition, or interfere with the production of pyrimidine repressors (15).

There is suggestive evidence that the rate of overproduction of UMP on day 2 of therapy is less than on days 8 and 20 and similarly that the extent of the block of decarboxylation is greater on day 2 than on days 8 and 20 . This suggests that there may not only be a prompt release of feedback inhibition but perhaps a progressive rise over several days of some or all of the enzymes in de novo pyrimidine production. Fallon, Frei, and Freireich (14) have demonstrated that clinical resistance to AzUR occurs at a time when the leukocytes' ability to decarboxylate $\mathrm{OA}$ is no longer inhibited by AzUR. This suggests that the therapeutic effectiveness of AzUR may lie in the differing abilities of normal tissue and leukemic leukocytes to increase de novo pyrimidine synthesis or intracellular pyrimidine precursor levels. Studies designed to investigate the possibility of a rise in enzymatic activity in normal and leukemic tissue during AzUR therapy and the relative rates of rise, if any, are underway.
The validity of the method used to estimate pyrimidine production in subjects receiving AzUR depends upon several assumptions. The first is that the metabolic pathways of de novo pyrimidine production are known. The second is that orotidine is produced by dephosphorylation of orotidylic acid and is a metabolically inert end product. The third is that steady-state conditions are approximated during the period of isotope administration and that pool assumptions are approximated. The last is that there does not exist a single population of cells that simultaneously violates both the postulates $\mathrm{A}$ and $\mathrm{B}$ (5) which follow: $A$ ) that the ratio of orotidine production to total pyrimidine production is the same for each cell population as for the whole body; $B$ ) that the ratio of $\mathrm{C}^{14}$-orotic acid to total orotic acid utilized by these cells is the same as that for the whole body.

The possibility of significant conversion of isotopes to other urinary products is minimal, since the correlation of total urinary radioactivity and the sum of urinary OR and OA radioactivity is good. Since urinary excretion of carbamylaspartic acid occurs, if retrograde isotope exchange took place, it would be expected to label this compound. This was not the case in the one patient studied.

If orotidine were substantially utilized via some other pathway (e.g., direct decarboxylation to uridine), then estimates of UMP production would be falsely large, since the rate of urinary excretion of OR would not represent its rate of production. However, orotidine has been shown not to dilute the radioactivity flowing from orotic acid to uridylic acid in vitro, nor is it a substrate for phosphorylases (16). A direct test of the inertness of intravenously administered orotidine-carboxyl- $\mathrm{C}^{14}$ was performed in this laboratory (17).

Trial calculations have shown that whole body variations from the steady state both in the rate of pyrimidine production and effectiveness of inhibition of decarboxylation by as much as $50 \%$ would not cause an overestimate of the average rate of production by more than a factor of two. An overestimate of the rate of production by a factor of five would require that the pyrimidine production be low with nq inhibition of decarboxy- 
lation for $90 \%$ of the interval and high with complete inhibition for $10 \%$ of the interval. This type of transient state seems very unlikely.

There is, however, a possibility that a cell population exists (the myeloid tissue) that may violate both postulates $A$ and $B$ as previously described. The myeloid tissue may, in the extreme, have decarboxylation completely blocked with its entire de novo pyrimidine production going to $\mathrm{OA}$ and $\mathrm{OR}$. Additionally the ratio of $\mathrm{C}^{14}$-orotic acid to total orotic acid converted to $\mathrm{OR}$ by this tissue would have to be less than that of the whole body. To overestimate pyrimidine production by a factor of 3 requires that this ratio in myeloid tissue be one-third of the ratio of the whole body, and this is a maximal value assuming the extreme of complete inhibition of decarboxylation in the myeloid tissue and no inhibition of decarboxylation in the rest of the body.

The example used to derive a minimal value for UMP production takes the extreme case of two cell populations, one utilizing no isotopic OA and with complete inhibition of decarboxylation of $\mathrm{OMP}$, and the second making no OA, utilizing isotopic OA, and not inhibited at all. To the extent that these conditions are not satisfied, the calculated UMP production rate during therapy is less of an overestimate, and the minimal UMP production rate estimate is a greater underestimate. The presence of isotopic urinary OR implies either utilization of isotope by the first cell population or partial inhibition of decarboxylation in the second cell population. In vitro studies with leukocytes isolated from subjects receiving AzUR have never shown complete inhibition of decarboxylation, which is what would be expected from a competitive inhibitor (14). Hence, no positive evidence is available to indicate that the first cell population may be completely inhibited. Thus, the conditions required for the minimal estimate of UMP production to be valid cannot be exactly met, and this minimal value is falsely low.

In addition, since clinical refractoriness to AzUR, which occurs after 2 to 3 weeks of therapy, is associated with a decreased inhibition of decarboxylation of orotic acid by leukocytes (14), it is more likely that overestimates will occur early in therapy. The data suggest, however, that overproduction is greater late in the course of therapy rather than early.

These considerations tend to support at least the qualitative validity of the values indicating that total body UMP production during some phases of therapy with AzUR in patients with CML is at least as great if not greater than the pretreatment rate.

Finally, a plausible alternative explanation for the relatively high production rate of decarboxylated pyrimidines in patients receiving prolonged courses of 6-azauridine would be as follows: If certain cell populations (the liver, for example) were not blocked in OMP decarboxylation, then, when presented with the excess orotic acid produced by other cells such as leukocytes, they might degrade amounts of OA via uridylic acid in excess of their normal total pyrimidine production.

\section{Summary}

The rate of de novo pyrimidine production was determined in three patients with chronic myelogenous leukemia before and during therapy with azauridine, an inhibitor of orotidylic acid decarboxylation. A fourth patient was studied only during therapy.

The pretreatment rates, estimated by the incorporation of intravenous orotic acid-6- $\mathrm{C}^{\mathbf{1 4}}$ into urinary pseudouridine, were $4.2,10.2$, and 15.9 mmoles per day. During therapy the rates, estimated by the incorporation of orotic acid-7-C ${ }^{14}$ into urinary orotidine, were $25.9,37.8,72.0$, and 147.6 mmoles per day. In addition the rates of production of uridylic acid during therapy estimated by this method were $11.8,13.3,56.0$, and 120.2 mmoles per day.

These data suggest that during some stages of therapy of chronic myelogenous leukemia with azauridine, there is no evidence for a decrease but instead perhaps evidence for an increase in the whole body rate of uridylic acid production.

\section{Acknowledgments}

The authors wish to express their appreciation to Mrs. Eleanor W. Barnes and Mrs. Louanna J. Baxter for their skillful technical assistance. 


\section{References}

1. Handschumacher, R..E., P. Calabresi, A. D. Welch, V. Bono, H. Fallon, and E. Frei III. Summary of current information on 6-azauridine. Cancer Chemother. Rep. 1962, 21, 1.

2. Reichard, P. The enzymatic synthesis of pyrimidines in Advances in Enzymology, F. F. Nord, Ed. New York, Interscience, 1959, vol. 21, p. 263.

3. Handschumacher, R. E. Orotidylic acid decarboxylase: inhibition studies with azaurdine 5'-phosphate. J. biol. Chem. 1960, 235, 2917.

4. Fallon, H. J., E. Frei III, J. Block, and J. E. Seegmiller. The uricosuria and orotic aciduria induced by 6-azauridine. J. clin. Invest. 1961, 40, 1906.

5. Weissman, S. M., A. Z. Eisen, H. Fallon, M. Lewis, and $\mathrm{M}$. Karon. The metabolism of ring-labeled orotic acid in man. J. clin. Invest. 1962, 41, 1546.

6. Bray, G. A. A simple efficient liquid scintillator for counting aqueous solutions in a liquid scintillation counter. Analyt. Biochem. 1960, 1, 279.

7. Smith, L. H., Jr., and F. A. Baker. Pyrimidine metabolism in man. I. The biosynthesis of orotic acid. J. clin. Invest. 1959, 38, 798.

8. Eisen, A. Z., S. Weissman, and M. Karon. Pseudouridine metabolism. I. Isolation and the effect of diet on urinary excretion. J. Lab. clin. Med. 1962, $59,620$.

9. Nathan, D. G., J. D. Davidson, J. G. Waggoner, and N. I. Berlin. The counting of barium carbonate in a liquid scintillation spectrometer. J. Lab. clin. Med. 1958, 52, 915.
10. Oliverio, V. T., C. Denham, and J. D. Davidson. Oxygen flask combustion in determination of $\mathrm{C}^{14}$ and $\mathrm{H}^{3}$ in biological materials. Analyt. Biochem. 1962, 4, 188.

11. Weissman, S., A. Z. Eisen, and M. Karon. Pseudouridine metabolism. II. Urinary excretion in gout, psoriasis, leukemia and heterozygous oroticaciduria. J. Lab. clin. Med. 1962, 59, 852.

12. Rabkin, M. T., E. W. Frederick, M. Lotz, and L. H. Smith, Jr. Pyrimidine metabolism in man. V. The measurement in vivo of the biochemical effect of antineoplastic agents in animal and human subjects. J. clin. Invest. 1962, 41, 871.

13. Cardoso, S. S., P. Calabresi, and R. E. Handschumacher. Alterations in human pyrimidine metabolism as a result of therapy with 6-azauridine. Cancer Res. 1961, 21, 1551.

14. Fallon, H. J., E. Frei III, and E. J. Freireich. Correlations of the biochemical and clinical effects of 6-azauridine in patients with leukemia. Amer. J. Med. 1962, 33, 526.

15. Kalousek, F., I. Rychlík, and F. Sorm. Inhibition of formation of acceptor sequence $\mathrm{pCpCpA}_{\mathrm{p}}$ in soluble ribonucleic acid by 6-azauridine-5'-diphosphate. Biochim. biophys. Acta (Amst.) 1962, 61, 368.

16. Pasternak, C. A., and R. E. Handschumacher. The biochemical activity of 6-azauridine: interference with pyrimidine metabolism in transplantable mouse tumors. J. biol. Chem. 1959, 234, 2992.

17. Weissman, S., V. Bono, and M. Lewis. Metabolic inertness of orotidine in man and the rat. Proc. Soc. exp. Biol. (N. Y.) 1963, 114, 682. 